\title{
Hebrew stress: Back to the future
}

\author{
Outi Bat-EI \\ Tel-Aviv University \\ obatel@post.tau.ac.il
}

\begin{abstract}
The paper addresses historical changes in the stress system of Hebrew, attending to the difference between Biblical Hebrew (script-based) and contemporary Hebrew (attested), and predicting the system of post-Hebrew; on the basis of experimental evidence and words from the periphery of the lexicon, it is predicted that the stress system of post-Hebrew will be similar to that of Biblical Hebrew. The predicted change from contemporary Hebrew to post-Hebrew is attributed to a combination of two factors: the inconsistency of the present system, and its incompliance with universal principles. The changes are addressed in terms of constraint reranking within the framework of Optimality Theory.
\end{abstract}

Keywords: Biblical Hebrew; Modern Hebrew; stress; trochee; historical change; Optimality Theory

\section{Introduction}

Contemporary Hebrew stress is not natural because it does not comply with universal principles which assign non-final stress in quantity insensitive systems (Hayes 1995). In addition, it is irregular and partially unpredictable due to the contrastive stress in the nominal paradigm (e.g., bókes 'morning' vs. bokés 'cowboy'). Given the combination of unnaturalness and irregularity, such a system has little chance to survive, and the seeds of change are already evident. ${ }^{1}$ The paper presents the evidence for the future change and analyzes the changes in the stress system in terms of constraint reranking. As it turns out, the future system will be similar to that of Biblical Hebrew; that is, Hebrew stress system seems to be going back to the future.

Stress in contemporary Hebrew is predominantly final, regardless of syllable structure. Vowel length is not contrastive, and syllables with and

${ }^{1}$ A reviewer asked whether the French stress system is unstable as well, given the unnatural final stress in a quantity insensitive language (ignoring, for the sake of argument, the debate as to whether stress in French is lexical or phrasal). As argued in Adam \& Bat-El (2009) and enhanced here, it is the combination of the two factors that makes the system unstable, i.e., both the irregularity and not complying with universal principles. As stress in French is not contrastive, its stability is secured relative to that of Hebrew. 
without codas are treated alike; therefore, there is no evidence for a moraic structure. However, this distribution of stress reflects mostly the lexicon, and to a lesser extent the speakers' preference. Experimental results reported in this study suggest that speakers prefer non-final stress, mostly penultimate. We take this pattern to be the natural selection, because it complies with universal tendencies and thus is also found in children's early speech. ${ }^{2}$

The preference for penultimate stress evident in the experimental studies is limited to vowel-final nouns; consonant-final nouns bear final stress. This contrast between C-final and V-final words is not supported by the distribution of stress in contemporary Hebrew, but strangely enough, it is found in Biblical Hebrew.

In this paper, I propose the predicted system of post-Hebrew, with word-final (but not medial) moraic codas and moraic trochaic feet. These structural properties allow the future patterns - final stress in C-final words and penultimate in V-final words. This is, indeed, a unique pattern, but probably an inevitable step in the course of change towards a natural and regular system - penultimate across the board.

In the ensuing section $\S 2$, I present the stress patterns in contemporary Hebrew, contrasting between the regular system in verbs $(\S 2.1)$ and the somewhat chaotic system in nouns (§2.2). Quantitative data display a contrast between a majority of final stress for native words and non-final stress for loan words $(\S 2.3)$. The seeds of change are revealed in $\S 3$, with two experimental studies (§3.1), one with acronym words and another with nonce words. Both experiments provide the same results - final stress in C-final words and penultimate in V-final words. These results comply with typologically-based universal principles and the children's early productions (§3.2). The analysis of the change in the stress system is given in $\S 4$ within the framework of Optimality Theory. I first present the predicted grammar of post-Hebrew (\$4.1), and then address the historical changes $(\S 4.2)$ : from contemporary Hebrew to post-Hebrew and from Biblical Hebrew to contemporary Hebrew. Concluding remarks are given in $\S 5$.

${ }^{2}$ A reviewer asked what makes trochee natural. Most languages exhibit a decline in the fundamental frequency (F0) at the end of a breath group in declarative intonation (Lieberman \& Blumstein 1998). The end of a phrase is thus characterized by a strongweak pattern, as in a trochaic foot. The decline in F0 is due to a fall in the subglottal air pressure, a physiological property common to all human species (see Vihman et al. 1998 for "biological tendencies"). 


\section{Contemporary Hebrew stress}

Verbs and nouns (including adjectives) are not alike when it comes to the stress patterns in contemporary Hebrew; unlike in nouns, the stress system in verbs is consistent, with only a handful of lexical exceptions, where lexical exceptions means exceptions that cannot be phonologically or morphologically classified. In order to appreciate the chaos in the noun system $(\S 2.2)$, the systematic stress in verbs is first presented $(\S 2.1)$.

\subsection{Systematic stress in verbs}

In suffixless verbs, stress is final (1a), with the exception of a few verbs ending with the historical guttural. ${ }^{3}$ Verbs with an agreement suffix may take final or penultimate stress, depending on the type of the base and the suffix. When the verb stem is monosyllabic, stress remains on the stem regardless of the type of the suffix; consequently, stress is penultimate in all suffixed forms. The same goes for stems with a high vowel in the final syllable (which surfaces as /a/ in a closed syllable followed by a suffix). Elsewhere, stress is final when the suffix is vowel-initial (1b) and penultimate when the suffix is consonant-initial (1c). Examples are given below for each of the three types, with the type frequencies of the stems in each group. ${ }^{4}$ Only past and future tenses are considered; the present tense is excluded because it is participial, whose behavior is adjectival (in many respects), including the stress patterns (Bat-El 2008).

Note that in the elsewhere case (rightmost column), the attachment of a V-initial suffix is accompanied with stress shift and vowel deletion (gamás- $a \rightarrow$ gamsá), but only when the penultimate stem syllable is open. When the penultimate syllable is closed, stress still shifts to the suffix but the stem vowel alternates with /e/ rather than deletes (tigmós- $i \rightarrow$ tigmesí).

${ }^{3}$ Verbs which historically ended in $\hbar, \mathcal{C}$, or $h$ are exceptional (less than $5 \%$ ), as they bear penultimate stress; e.g., iftia 'surprised' (<*hiftia $)$, ivtia 'promised' (<*hivtia $)$. Most of these verbs are identified on the basis of the $V_{1} V_{2}$ sequence, where $V_{2}$ is /a/.

${ }^{4}$ The frequency count is based on Bolozky's (2008) list of the most frequent verbs in Hebrew, 499 types and 107,984 tokens in a corpus of 5.3 tokens corresponding to a quarter-of-a-million types. The corpus is based mostly on journalistic texts from Haaretz, Maariv and Yedi'oth Aharonot (2006-2008), and some literary pieces (middle register). 
Given such a consistent system, there is no contrastive stress among verbs of the same morphological structure. For different morphological structures, there are a few minimal pairs such as the bare stem satsá 'he wanted' vs. the suffixed form sáts-a 'she ran'. Across lexical categories, there are also minimal pairs like the noun náxal 'river' vs. the verb naxál 'inherit'.

(1) Stress patterns in Hebrew verbs (penultimate shaded)

\begin{tabular}{|c|c|c|c|c|c|c|}
\hline & & & & $\begin{array}{l}\text { Stems with } \\
\mathrm{V}_{[+ \text {high }]}\end{array}$ & $\begin{array}{l}\text { Monosyllabic } \\
\text { stems }\end{array}$ & Elsewhere \\
\hline \multicolumn{4}{|c|}{ Frequency (type): } & $20 \%$ & $3 \%$ & $77 \%$ \\
\hline \multirow[t]{2}{*}{ a. } & No suffix & 3.Ms.SG. & PAST & itxíl & kám & gamás \\
\hline & & 2.Ms.SG. & Fut. & ta-txíl & ta-kúm & ti-gmós \\
\hline \multirow[t]{2}{*}{ b. } & V-initial & 3.FM.SG. & PAST & itxíl-a & kám-a & gamı-á \\
\hline & suffix & 2.FM.SG. & FuT. & ta-txíl-i & ta-kúm-i & ti-gmев-í \\
\hline \multirow[t]{3}{*}{ c. } & C-initial & 1.SG. & PAST & itxál-ti & kám-ti & gamás-ti \\
\hline & suffix & 2.PL. & Past & 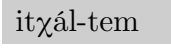 & kám-tem & gamás-tem \\
\hline & & & & 'to start' & 'to get up' & 'to end' \\
\hline
\end{tabular}

Taking into consideration the surface stress patterns of the 499 most frequent verbs with their 16 finite verb forms in the past and future tenses, $68 \%(5418 / 7984)$ of the verb forms are stress-final.

\subsection{Contrastive stress in nouns}

Hebrew nouns (and adjectives) display three stress patterns, final penultimate and antepenultimate, which are often lexically contrastive, i.e., cannot be predicted by the phonological structure of the word and thus must be memorized. As shown below, in all three stress patterns stress can reside on syllables with or without a coda (Bat-El 1993; 2005; Graf 1999; Bolozky 2000). We take codas as a potential source of contrast, given languages where syllables with codas attract stress (Gordon 2006). 
(2) Contrastive stress in nouns

\begin{tabular}{|c|c|c|c|}
\hline Stressed syllable & Final & Penultimate & Antepenultimate \\
\hline \multirow{3}{*}{ Without coda } & kitá 'class' & sáfta 'grandma' & béjgale 'pretzels' \\
\hline & smixá 'blanket' & avokádo 'avocado' & bsókoli 'broccoli' \\
\hline & xatuná 'wedding' & ambátja 'bath tab' & básbikju 'barbecue' \\
\hline \multirow[t]{3}{*}{ With coda } & 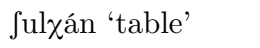 & tísas 'corn' & ámbulans 'ambulance' \\
\hline & kadús 'ball' & mástik 'gum' & fókolad 'chocolate' \\
\hline & afausék 'peach' & sakévet 'train' & télefon 'phone' \\
\hline
\end{tabular}

Antepenultimate stress is rare, limited to loan words, and will thus be ignored. Final stress is the most frequent pattern (see counts in §2.3), but penultimate stress is also present. The contrast is thus primarily between final and penultimate stress.

In addition to the contrastive stress, there are instances of free variation, where both final and penultimate stress are possible (e.g., sukав 'sugar', uga 'cake', asfalt 'asphalt', Jampo 'shampoo', tlufim 'coupons'). While this is often an inter-speaker variation, for some words (and some speakers) the variation is lexicalized, such that each pattern denotes a different though related meaning (e.g., bubá 'toy doll' vs. búba 'wonderful', klafim 'cards' vs. kláfim 'card game'). Variation is also found in personal names (Bat-El 2005), where penultimate stress prevails among the younger generation.

An additional lexical property is found in the morphological paradigm, where the contrast between fixed and mobile stress is manifested (BatEl 1993). In some paradigms, which include mostly, but not exclusively, loanwords and acronym words (Bat-El 1994; 2000), stress is fixed in its position on the stem, giving rise to non-final stress in suffixed forms (3a). More common, however, in particular in native words, are the cases where stress shifts to the suffix, giving rise to final stress (3b).

(3) Contrast in the morphological paradigm

\begin{tabular}{|c|c|c|c|c|c|}
\hline Fixed str & & & Mobile s & ress & \\
\hline Singular & Plural & & Singular & Plural & \\
\hline $\begin{array}{l}\text { tut } \\
\text { xamsín }\end{array}$ & $\begin{array}{l}\text { tútim } \\
\text { xamsínim }\end{array}$ & $\begin{array}{l}\text { 'strawberry' } \\
\text { 'hot wind' }\end{array}$ & $\begin{array}{l}\text { xut } \\
\text { tavlín }\end{array}$ & $\begin{array}{l}\text { xutím } \\
\text { tavliním }\end{array}$ & $\begin{array}{l}\text { 'thread' } \\
\text { 'spices' }\end{array}$ \\
\hline lókes & lókевim & 'locker' & kétes & ktasím & 'crown' \\
\hline
\end{tabular}

The contrast between nouns with mobile and fixed stress roughly corresponds to the contrast between native and loan nouns respectively. It is important to say 'roughly' because loanwords may gain mobility and native 
words may lose it (Becker 2003). The loanword balón 'balloon', for example, has fixed stress in the speech of the older generation but mobile in the speech of youngsters (plural: balónim - balonim respectively). Similarly, the native word masák 'soup' often takes fixed stress in its plural form masákim 'types of soup'.

The above data and generalizations reflect not only lexical contrast but also variation. The latter is a sign of a future change, which will be supported in $\S 3.1$ by data from experimental studies. But first, I provide the quantitative distribution of stress in contemporary Hebrew nouns.

\subsection{The distribution of stress in nouns}

If we consider all nouns in Bolozky and Becker's (2006) Living Lexicon, final stress constitutes about $75 \%$. Note that these are noun stems, and the percentage will be even higher if we count suffixed forms. Bolozky and Becker's lexicon includes quite a few loanwords that are structurally unique with respect to length (four and five syllables) and syllable structure. To exclude these words, I use Fainleib's (2013) sub-corpus of the Living Lexicon, which includes native-like words - with two-three syllables, CV and/or CVC. In this sub-corpus, consisting of 6811 noun types, $79 \%$ ( $n=5361)$ of the nouns bear final stress (cf. the distribution of verbs in $\S 2.1$, with $95 \%$ final stress in stems and $68 \%$ final stress when all forms of the tense paradigm are considered).

Much of the non-final stress is attributed to loanwords, which constitute $13 \%(n=853)$ of the native-like words. Out of these loanwords, only $36 \%(n=304)$ are stress-final, compared to native words where $85 \%$ $(n=5057)$ are stress-final. Another property distinguishing between native words and loanwords is the significance of the final segment. In native words (4a), C-final and V-final words behave alike with respect to their preference for final stress. In native-like loanwords, according to (4b), the final segment is significant; V-final words prefer penultimate stress while C-final words prefer final stress.

Being at the periphery of the lexicon (Itô \& Mester 1995; Itô \& Mester 1999; Paradis \& LaCharité 1997; LaCharité \& Paradis 2005), Hebrew loanwords reside in an independent stratum (Becker 2003), as they often display unique phonological properties; they may include non-native consonants (e.g., /3/ in gава́z 'garage'), triconsonantal codas (e.g., /nkt/ in instinkt 'instinct'), and consist of more than three syllables (Schwarzwald 1998). 
However, Hebrew loanwords have shown to allow the emergence of the unmarked (Cohen 2009; 2013), as do other word types in the periphery of the lexicon (Bat-El 2000). The unmarked structures also arise in experimental studies and in the early speech of Hebrew-acquiring children, as shown in the following section.

(4) The distribution of stress patterns - native vs. loan words (Fainleib 2013)

a. Native words $(n=5958)$

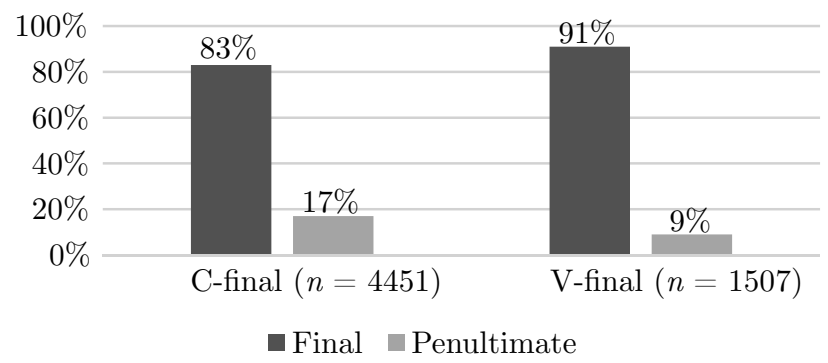

b. Loan words $(n=853)^{5}$

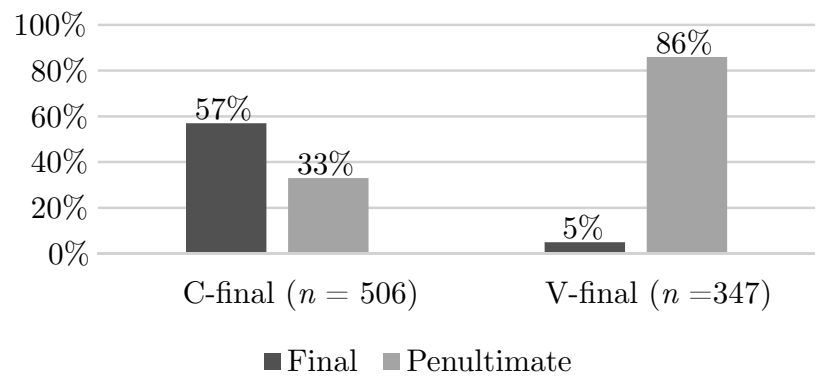

\section{Seeds of change}

As shown above, stress in contemporary Hebrew is predominantly final, but there seem to be sporadic signs of change towards penultimate stress. Importantly, this change is not limited to loanwords. The experimental data presented below (§3.1) confirm the suggested direction of change towards penultimate stress. This is a natural direction of change (§3.2), evident also in the early productions of Hebrew-acquiring children.

${ }^{5}$ Antepenultimate stress appears in $9 \%(n=32)$ of the V-final loan words and in $10 \%$ $(n=53)$ of the C-final. 


\subsection{Experimental studies}

Two experiments were conducted independently (with about 10 years gap between them), one with acronym words (§3.1.1) and another with nonce words (§3.1.2); the two experiments provide similar results. Crucially, the results do not comply with the distribution of stress in the lexicon of contemporary Hebrew, and they are thus not based on lexical frequency in Hebrew.

\subsubsection{Acronym words}

Hebrew acronym words are structurally identical to the most frequent native core stems, which are also the least marked ones (Bat-El 1994; 2000); they are usually disyllabic, their syllables are free of complex subsyllabic units, and their vowel is often $/ \mathrm{a} /{ }^{6}$

(5) Acronym and native words

\begin{tabular}{llll}
\multicolumn{2}{l}{ Acronym words } & \multicolumn{2}{l}{ Non-acronym words } \\
alám 'colonel' & agám 'lake' \\
mankál & 'CEO' & sakdán 'dancer.Ms.SG' \\
báhad 'training base' & láhag 'dialect' \\
tába 'city planning' & sába 'grandfather' \\
вá $j$ 'a name' & вáfi 'a name'
\end{tabular}

With regard to stress, acronym words tend to bear non-final stress more than native words, in particular when they end in a vowel. Moreover, when a suffix is added, in most cases stress is fixed, i.e., it remains on the stem (cf. sakdanim 'dancers' vs. acronym word mankálim 'CEOs'). There are various acronym lists and dictionaries which are not reliable with respect to their use, in particular given that the stress and the vocalic pattern are not specified due to the orthographic system of Hebrew. An experiment was thus conducted in order to determine whether the preferred stress pattern in acronym words is indeed non-final.

Nineteen monolingual Hebrew speakers, five males and fourteen females (mean age: 23), read 24 unfamiliar acronym words and their bases

${ }^{6}$ Zadok (2002) claims that Hebrew acronym words are actually clipped compounds, where the base vowels are often replaced with the most frequent vowel /a/, as in datláf from dati lifamim 'sometimes religious'. However, it is immaterial to the present discussion whether these are acronym words or clipped compounds, because either way they reside in the periphery of the lexicon, despite of their structural similarity with core stems. 
from a screen; 12 of these were C-final and $12 \mathrm{~V}$-final. The participants were seated in a quiet room in front of a computer screen, where the acronym words appeared on the screen in their orthographic forms in a random order, and the words composing them were displayed below. The participants were requested to produce both the acronym word and the sequence of words from which it was composed. The participants' productions were transcribed by a trained phonetician.

The experiment was visual in order for the participants to realize that these are acronym words. Not only did we provide the bases for the acronym words, we also wrote the acronym words with a single quote, which distinguishes them from other words in the Hebrew script. For example, báhad and láhag are written להג and respectively, where בה"ד is identified as an acronym word due to the single quote preceding the final letter (note that Hebrew is written right-to-left).

The results of the experiment revealed a slight preference for final stress $(55.6 \% ; 239 / 430)$, which was statistically significant $(p<0.0001$; FET) with the expectation of $75 \%$ final stress found in Hebrew noun types. In addition, the difference between C-final vs. V-final forms was also significant $(p<.001 ; \mathrm{FET})$, showing a preference for penultimate stress in V-final words $(83 \% ; 178 / 214)$ and final stress in C-final words $(94 \% ; 203 / 216)$. Similar correlation between stress and final segment was found in an experimental study of Greek acronym words (Revithiadou et al. 2015).

(6) Stress in the acronym words' experiment - 55.6\% (239/430) final stress

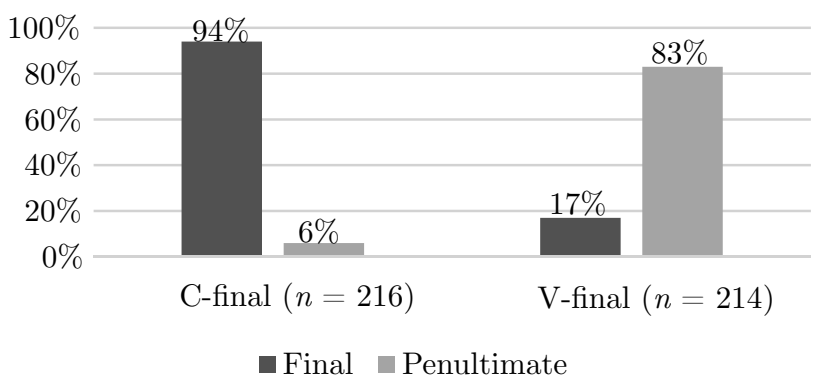

The results of the experiment do not reflect the distribution of stress in Hebrew native nouns, despite the fact that, as shown in (5), acronym words structurally resemble native core Hebrew words, and they do not manifest the common characteristics of loanwords. As shown below, similar results were obtained from an experiment with nonce words. 


\subsubsection{Nonce words}

An experiment with nonce-words is reported in Fainleib (2008), with twelve monolingual native Hebrew speakers (mean age: 23), eight males and four females. The participants were asked to embed 144 nonce nouns in two sentence frames, one requiring the singular form and the other requiring the plural form. There were di- and trisyllabic nonce words in the experiment, half $\mathrm{C}$-final and half $\mathrm{V}$-final. In addition, half of the words included vocalic patterns that are frequent in Hebrew nouns (e.g., $a-a$ as in sapár 'hairdresser', $a-i$ in fatil 'plant' ) and half included vocalic patterns that are rare or non-existing in the language.

(7) Stress patterns in C-final vs. V-final nonce words (Fainleib 2008)

a. High frequency vocalic patterns $(n=859)$

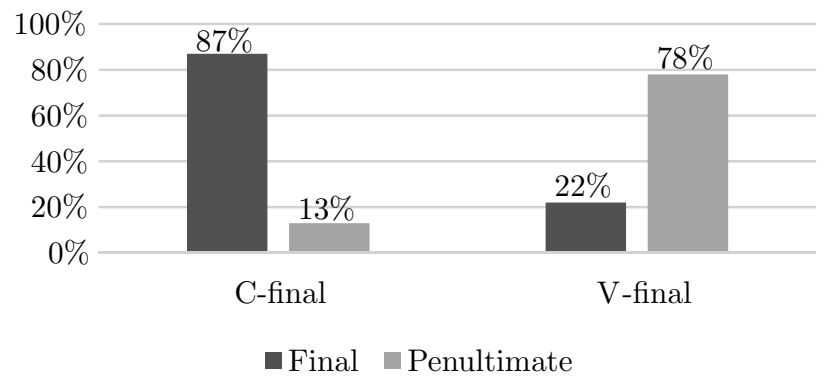

b. Low frequency vocalic patterns $(n=861)$

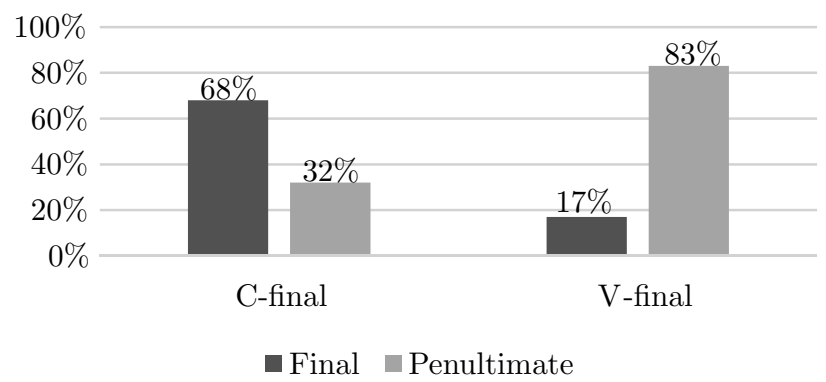

As the results in (7) suggest, native Hebrew speakers incline towards the distribution of stress found in loan words more than in Hebrew native words, with a preference for final stress in C-final words and penultimate stress in V-final words (all differences were statistically significant; see Fainleib 2008). As expected, the preference for penultimate stress in gen- 
eral is more prominent in the nonce words with the low frequency vocalic patterns (7b), where the speakers' lexicon has a lower chance of influencing the outcome of the experiment, due to the greater dissimilarity between the nonce words and the words in the Hebrew lexicon.

\subsection{The natural stress pattern}

The experiments' results reflect a stress system that differs from the one found in the native lexicon of Hebrew: (i) there is a preference for penultimate stress in the experiments' results but not the core lexicon, and (ii) a sensitivity to the final segment (C vs. V) appears in the experiments' results but not in the core lexicon.

A preference for penultimate stress is found also in early productions of Hebrew-acquiring children. Hebrew stress is predominantly final also in child directed speech (Segal et al. 2009), but nevertheless, Hebrewacquiring children attempt producing more words with penultimate stress than with ultimate, and also produce more words with penultimate stress than with ultimate (Adam \& Bat-El 2008; 2009; Ben-David \& Bat-El 2016). The data below, drawn from a longitudinal study of one child (Adam \& Bat-El 2009), show that penultimate stress is predominant in early productions (8a), and that truncation to monosyllabic productions persists longer for target words with final stress (8b). These indicate that children try avoiding final stress in polysyllabic words, and are comfortable with words with non-final stress from very early stages.

(8) Child's preference for penultimate stress (Adam \& Bat-El 2008; 2009)

a. Polysyllabic productions (\%)

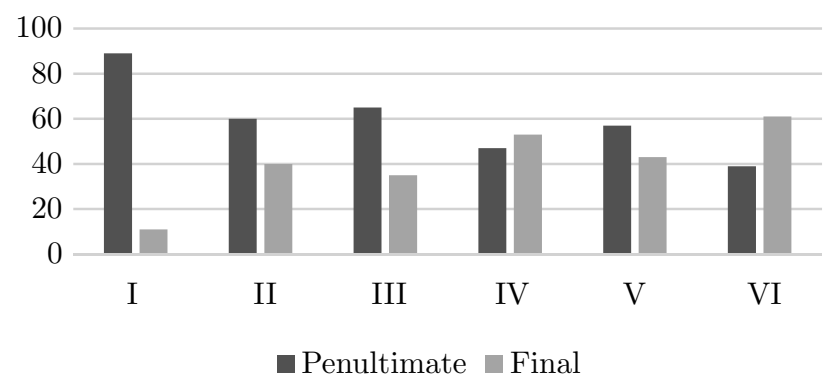


b. Truncation to monosyllabic (\%)

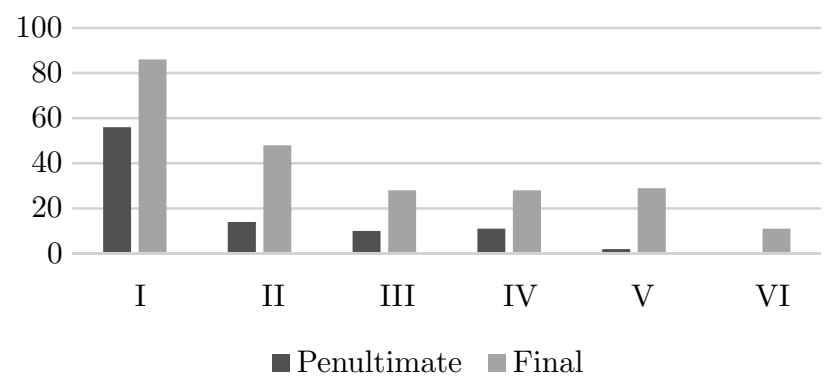

The Roman numerals in (8) indicate periods of development, based on the child's cumulative attempted words (I - 10 words, II - 50 words, III - 100 words, IV -150 words etc.). Thus, only after the child had 100 word types in his production lexicon (i.e., period III), did he start shifting towards final stress.

All the Hebrew-acquiring children we studied refrain from final stress in their early polysyllabic productions, using two repair strategies. ${ }^{7}$ Most children prefer to truncate words to monosyllabic productions but some prefer to shift stress away from the final syllable (9). These repairs are found mostly in target words with final stress; words with penultimate stress are produced as disyllabic from a very early stage (Ben-David 2001).

(9) Children's repair strategies for targets with final stress

\begin{tabular}{|c|c|c|}
\hline Target & Truncation & Stress shift \\
\hline lekaléf 'to peel' & jef & kájef \\
\hline zipufít 'beetle' & 3it & búzit \\
\hline lifón 'to sleep' & son & jíson \\
\hline kasnáf 'rhino' & naf & ánaf \\
\hline
\end{tabular}

This inter-child variation is not due to input frequency, as evident by data from twin boys, where until the age of 1:6, one used truncation in $50 \%(110 / 218)$ of the iambic targets and the other used stress shift in $52 \%(127 / 245)$. Keeping stress in its target final position in polysyllabic productions was the least favorite strategy for both, with $22 \%(47 / 218)$ for the truncation boy and 13\% (33/245) for the stress shift boy.

7 This statement is based on Ben-David's (2001) study of 10 children, which is further supported by a case study presented in Adam and Bat-El (2008; 2009), and unpublished data of 5 additional children. 
Assuming a trochaic foot for non-final stress, the children's preference reflects the universal trochaic bias (Allen \& Hawkins 1978). Hebrew is expected to be a trochaic language, like most quantity insensitive languages (Hayes 1995), where syllable weight is not contrastive. However, due to historical reasons (see $\S 4.2 .2$ ), this expectation is not born out in the core lexicon. The children, however, adhere to the expected universal stress pattern in early stages, until they realize that frequency does not support it.

Thus, beyond being unsystematic, the stress system of nouns in contemporary Hebrew is unnatural, i.e., marked. This combination makes the system fragile and subject to future change. The children's early productions and the experiments' results reflect the default natural stress.

\subsection{The predicted post-Hebrew stress system}

The experiments' results reveal a preference for final stress in C-final words and penultimate stress in V-final words. This, I propose, is quite likely to be the future of Hebrew stress. As shown below, the predicted metrical structure consists of moraic codas at the end of the word and right-aligned moraic trochees. Note that as moraic codas appear only at the end of the word; in non-final position, a syllable equals a mora regardless of whether it is $\mathrm{CV}$ or $\mathrm{CVC}$.

(10) Post-Hebrew metrical structure

a. Final

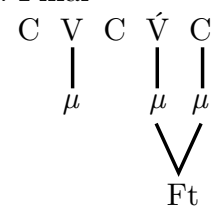

b. Penultimate

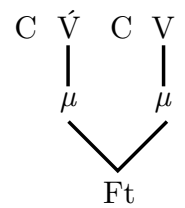

c. Penultimate

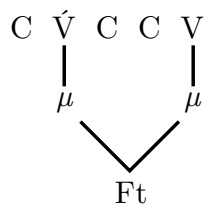

Within the constraint-based framework of Optimality Theory (Prince and Smolensky 1993), the moraic structure in (10), where only final codas are moraic, is assigned by the ranking $\mathrm{W}-\mathrm{BY}-\mathrm{P}]_{\omega} \gg \mathrm{DEP}_{\mu} \gg \mathrm{W}-\mathrm{BY}-\mathrm{P}$; the constraint W-By-P (Weight-By-Position), which assigns moras to codas (Hayes 1989), competes with $\mathrm{DEP}_{\mu}$, which prohibits adding moras (assuming that codas are not moraic in the input). Notice the proposed distinction between the specific $\mathrm{W}-\mathrm{BY}-\mathrm{P}]_{\omega}$, which assigns moraic codas in word final position, and the general W-BY-P, which assigns moraic codas 
across the board. ${ }^{8}$ With $\operatorname{DEP}_{\mu}$ between the two, we get moraic codas at the end of the word $\left.(\mathrm{W}-\mathrm{BY}-\mathrm{P}]_{\omega} \gg \operatorname{DEP}_{\mu}\right)$ but not elsewhere $\left(\operatorname{DEP}_{\mu} \gg\right.$ $\mathrm{W}-\mathrm{BY}-\mathrm{P})$. This is the novelty of post-Hebrew - word final moraic codas. As I show in $\S 4.2$, Biblical Hebrew had the same system. ${ }^{9}$

Contemporary Hebrew does not have lexical secondary stress (Becker 2002; Cohen et al. 2018), and there are no signs that post-Hebrew will develop it. Therefore, I assume that footing is not exhaustive, i.e., there is only one foot in a prosodic word (e.g., $\left\{a m[b a ́ t j a]_{\mathrm{Ft}}\right\}_{\mathrm{PrWd}}$ 'bath tab').

As stress is mostly final or penultimate, feet are right-aligned with the prosodic word, with Align(FT, PrWd) outranking PARSE; that is, a prosodic word with unparsed syllables is better than one with feet that are not right-aligned (e.g., $\{a . v i[$ เón $]\}$ 'airplane' is better than $\{[a . v i][$ เón] $\}$ ). At the bottom of the hierarchy, along with PARSE, is NonFinality, which prohibits stressed syllables to align with the right edge of the word.

Thus, with right-aligned binary moraic trochees, the stress grammar of post-Hebrew will be as follows:

(11) Post-Hebrew stress grammar (predicted)
a. W-BY-P $]_{\omega} \gg \operatorname{DEP}_{\mu} \gg \mathrm{W}-\mathrm{BY}-\mathrm{P}$
b. Trochee $\gg \operatorname{Iamb}($, FinalStress)
C. FtBin, ${ }^{*}$ Foот- $\sigma \gg{ }^{*}$ Foot $\mu$
d. AlignR(Ft, PrWd) $\gg$ NonFinality, Parse

The ranking in (11a) assigns a mora to word final codas; (11b) ensures trochaic feet; (11c) is responsible for the feet being binary moraic; and (11d) places one foot only (ALIGNR $\gg$ PARSE) at the right edge of the prosodic word (AlignR $\gg$ NonFinality). FinalStress (aka RightMOST StRESSED $\sigma$ ), which assigns stress to the final syllable of the word, does not affect the system in its position below TROCHEE (11b); however, it will become relevant in the discussion on contemporary Hebrew.

$\left.{ }^{8} \mathrm{~W}-\mathrm{BY}-\mathrm{P}\right]_{\omega}$ is actually WeIGHT-BY-Position-BY-Position, where the first position is the coda and the second is the right edge of the word.

${ }^{9}$ This proposed system is indeed more complex than one with moraic codas across the board, but it could just be a step in a change towards a system with syllabic trochees and thus penultimate stress across the board (see $\S 5$ ). 


\section{Back to the future}

The stress patterns predicted for post-Hebrew are found in earlier stages of the language - in Biblical Hebrew. That is, Hebrew stress system is going back to the future. In this section, I present the historical changes in terms of constraint reranking, from contemporary Hebrew to post-Hebrew (§4.1) and from Biblical Hebrew to contemporary Hebrew (§4.2).

\subsection{From contemporary Hebrew to post-Hebrew}

There are three competing analyses of the contemporary Hebrew stress system within the framework of Optimality Theory - Becker (2002), Graf \& Ussishkin. (2002), and Pariente \& Bolozky (2014). The foot assignment of the three analyses is given below.

(12) Foot assignment

\begin{tabular}{lll}
\hline & Penultimate & Final \\
\hline Becker (2002) & [jélled & ka[dús] \\
Graf \& Ussishkin (2002) & [jéled] & [kadús] \\
Pariente \& Bolozky (2014) & [jéled] & ka[dús] \\
& 'boy' & 'ball' \\
\hline
\end{tabular}

All three analyses accept the contrast between fixed and mobile stress (3), and assume lexical marking for words with fixed stress (Bat-El 1993); I do not address this issue in the present discussion. The above analyses also agree that feet are syllabic, but they differ in three properties: whether feet must align with the prosodic word (13a), whether feet must be trochaic (13b), and whether feet must be binary (13c).

(13) Differences among the analyses

\begin{tabular}{llccc}
\hline & & $\begin{array}{c}\text { Becker } \\
(2002)\end{array}$ & $\begin{array}{c}\text { G. \& U. } \\
(2002)\end{array}$ & $\begin{array}{c}\text { P. \& B. } \\
(2014)\end{array}$ \\
\hline a. Feet are right-aligned with the PrWd & no & yes & yes \\
b. Feet are trochaic & yes & no & yes \\
c. Feet are binary syllabic & no & yes & no \\
\hline
\end{tabular}


The mixed system proposed in Graf \& Ussishkin (2002) better expresses the inconsistency of stress assignment in contemporary Hebrew, but the trochaic feet proposed in Becker (2002) are gradually taking over.

The last two properties in (13) reflect the desired unmarked system binary trochaic feet. These two properties cannot both hold for contemporary Hebrew, where feet are syllabic and stress can be final or penultimate. Any analysis must admit a marked structure, either iambic feet (e.g., [sibá] 'reason') or non-binary feet (e.g., si[bá]).

Crucially, the above analyses do not attend to the contrast between C-final and V-final words, and with a good reason - this contrast is relevant only to loan words and acronym words in contemporary Hebrew, which are in the periphery of the lexicon, thus constituting a small percentage of the vocabulary. However, the experiments' results reported in $\S 3.3$ above strongly suggest that speakers attend to the contrast between C-final and $\mathrm{V}$-final words. The fact that speakers attend to a contrast that is only marginally supported by their lexicon suggests that this is a newly growing property of their grammar; therefore we can predicted that it will grow further towards post-Hebrew (other things being equal).

Two constraints will be demoted in the course of the predicted development from contemporary Hebrew to post-Hebrew - DeP $\mu$ and FinALSTRESS (here after FINAL); the latter is employed in two out of the three analyses of contemporary Hebrew (Becker 2002, Graf and Ussishkin 2002). $\operatorname{DEP}_{\mu}$ will be violated in word final position with the addition of a mora to a final consonant, and FINAL will be violated in V-final words where stress will reside on the penultimate syllable.

(14) From contemporary Hebrew to post-Hebrew: constraint demotion

\begin{tabular}{|c|c|c|}
\hline \multicolumn{2}{|r|}{ Contemporary Hebrew } & Post-Hebrew \\
\hline a. & $\left.\operatorname{DEP}_{\mu} \gg(\mathrm{W}-\mathrm{BY}-\mathrm{P}]_{\omega} \gg\right)$ W-BY-P & $\mathrm{W}-\mathrm{BY}-\mathrm{P}]_{\omega} \gg \mathbf{D E P}_{\mu} \gg \mathrm{W}-\mathrm{BY}-\mathrm{P}$ \\
\hline $\mathrm{b}$ & FinAL $\gg$ TrocheE $\gg$ IAMB & Trochee $\gg$ Iamb, Final \\
\hline c. & FTBIN, ${ }^{*} \mathrm{~F}$ & ${ }^{*}$ Fоот $-\mu$ \\
\hline d. & AlignR $\gg I$ & LITY, PARSE \\
\hline
\end{tabular}

Codas in contemporary Hebrew are not moraic, and thus $\operatorname{DEP}_{\mu}$ is ranked above W-BY-P. In post-Hebrew, final codas are predicted to become moraic, and therefore the change in (14a) will involve demotion of $\operatorname{DEP}_{\mu}$ below $\mathrm{W}-\mathrm{BY}-\mathrm{P}]_{\omega}$ (which is overshadowed by the general constraint in contemporary Hebrew). 
Feet in contemporary Hebrew are syllabic and final stress is predominant; therefore, the constraint FINAL dominates TROCHEE $\gg$ IAMB; any surface non-final stress requires either lexical marking (Bat-El 1993; Becker 2003) or some type of paradigmatic effect (Graf \& Ussishkin. 2002). Evidence for the ranking TROCHEE $\gg$ IAMB in contemporary Hebrew is drawn from hypocoristics, where the effect of TrocheE emerges (Bat-El 2005). The ranking FINAL $\gg$ TROCHEE $\gg$ IAMB allows marked structures, either iambic feet (Graf \& Ussishkin. 2002) or degenerate feet (Becker 2002; Pariente \& Bolozky 2014). The demotion of Final in post-Hebrew (14b), which renders it irrelevant, gives rise to trochee.

The last two rankings in (14) will remain intact, though the role of (14c) will change. The ranking *FоOT- $\sigma \gg{ }^{*}$ FоOT- $\mu$ is not relevant in contemporary Hebrew since a mora equals a syllable, but it will become relevant in post-Hebrew, where final CVC will be bimoraic. FTBIn will remain dominant, as in Graf and Ussishkin's (2002) analysis, but feet will be moraic; thus as in Becker (2002) and Pariente \& Bolozky (2014), final stressed CVC will constitute a foot.

\subsection{From Biblical Hebrew to contemporary Hebrew}

A remarkable point in the developing post-Hebrew stress system is its similarity to Biblical Hebrew. Stress in Biblical Hebrew was, in most cases, final in C-final words and penultimate for $\mathrm{V}$-final words (see below for a few cases where this generalization does not hold). This system developed from penultimate stress in pre-Hebrew, due to the deletion of word final unstressed vowels (Churchyard 1999; Florentin 2002; Khan 2013b; Blau 2010).

Starting with the development of Lieberman and Prince's (1977) Metrical Grid Theory, the Biblical Hebrew stress system was analyzed in various studies, including McCarthy (1979); Hayes (1980; 1995); Dresher (1981; 2009); Rappaport (1984), and Halle \& Vergnaud (1987). The analysis goes roughly as follows (ignoring differences among these studies):

(15) Stress assignment within the Metrical Grid Theory

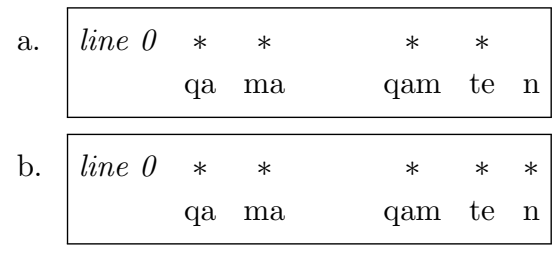

Assign a line 0 asterisk to all syllables (or vowels).

Assign a line 0 asterisk to a word final consonant. 


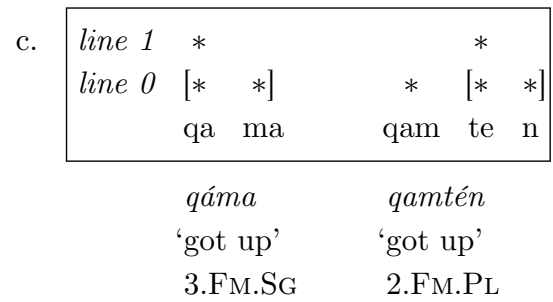

Construct a bounded leftheaded foot at the right edge of the word

The translation of this system into a constraint-based approach is straightforward. Rule (15b), 'Assign a line 0 asterisk to a word final consonant', implies that word final codas are moraic, and thus reflects the effect of W-BY-P $]_{\omega}$. In Biblical Hebrew, however, all codas are moraic, as evident by the process of compensatory lengthening (Lowenstamm \& Kaye 1986; Hayes 1989). Therefore, the relevant constraint is the general W-BY-P, which outranks $\operatorname{DeP}_{\mu}$ (16a).

Rule (15c), 'Construct a bounded left-headed foot at the right edge of the word', implies a binary moraic trochaic foot, thus reflecting the effect of TrocheE (16b), as well as the preference of a moraic foot over a syllabic foot (16c). However, unlike post-Hebrew, Biblical Hebrew has secondary stress and thus PARSE outranks ALignR (16d). Secondary stress is, however, not assigned to adjacent syllables due to * CLASH, but I ignore this issue due to its irrelevance to the other stress systems discussed here.

(16) Biblical Hebrew stress grammar
a. $\mathrm{W}-\mathrm{BY}-\mathrm{P} \gg \mathrm{DEP}_{\mu}$
b. Trochee $\gg \operatorname{Iamb}($, Final $)$
c. FtBin, ${ }^{*}$ Foot $-\sigma \gg *$ Foot $\mu$
d. Parse $\gg \operatorname{AlignR}(F t$, PrWd $) \gg$ NonFinality

A major part of the native vocabulary of contemporary Hebrew is drawn from Biblical Hebrew, although the path of change was not direct. ${ }^{10}$ The

${ }^{10}$ Biblical Hebrew was attested since ca. 1100 BCE, but died out as a spoken language with native speakers in the 3rd century CE. This period includes various sub-periods and dialects which are not relevant for the present study (see Rendsburg 2007 and references therein for details regarding the phonological development). Contemporary Hebrew (aka. Modern Hebrew or Israeli Hebrew) became a spoken language with native speakers in the late 19th and early 20th century. The emphasis is on 'native speakers' and 'spoken language', since Hebrew has been used throughout this time for liturgical and literary purposes. There is a debate as to whether Biblical Hebrew is the genetic ancestor of contemporary Hebrew (Horvath \& Wexler 1994), but this issue is not relevant here, nor are the complex and controversial details of the development 
primary written source of Biblical Hebrew is the Tiberian texts, where stress is indicated with the accentual markers of the phrasal prosodic structure (Aronoff 1985; Dresher 1994). Every prosodic word carries an accentual marker, and most markers are placed on the onset of the stressed syllable (not on the vowels, since most vowels are marked with diacritics). Some markers have a fixed position, either on the initial or final letter in the word, but occasionally they appear twice within a word, in their fixed position and on the stressed syllable.

The accentual markers are exemplified in (17) below, with the phrase 'In the beginning God created the heavens and the earth' (Genesis 1:1). The accentual markers (line $d$ in (17)), copied from the script (line c), correspond to the stress markers in the phonetic transcription (line b). Recall that Hebrew is written right-to-left.

(17) Stress marking in the Tiberian script of Biblical Hebrew ${ }^{11}$
a. the-earth and-ACC

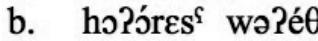
ACC. God
created in the beginning
c. הָָָרָּ
וֵيֵת

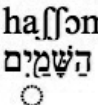

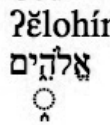

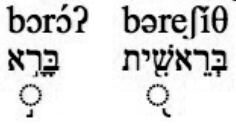

The fact that the normative stress patterns of contemporary Hebrew are in most cases identical to those of Biblical Hebrew suggests that the information provided by the script was attended during the emergence of Hebrew as a spoken everyday language. I thus treat Biblical Hebrew as the main lexical source of contemporary Hebrew and discuss the differences between the two in terms of historical change (thus skipping possible intermediate changes in between).

Stress in Biblical Hebrew was relatively consistent. Most stems ended in a consonant, and were thus stress-final. In suffixed forms, the contrast between C-final and V-final forms was maintained, though nouns only had C-final suffixes. ${ }^{12}$

Due to various phonological processes, the contrast between V-final and C-final words was not always surface true. There are two cases where

of Hebrew. Regardless of one's view on the matter, there is no doubt that a great deal of the morphological paradigms in contemporary Hebrew, including morphophonological alternations and stress patterns, were drawn primarily from Biblical Hebrew.

11 The transcription ignores the disputed vowel length (Khan 2013c). ACC stands for the accusative marker, a pro-clitic of definite nouns.

12 The discussion excludes the possessive markers (e.g., Pimm-ó 'his mother'), which are not suffixes but rather clitics (i.e., syntactic). 
V-final words surface with final stress, rather than the expected penultimate stress: (a) word final glottal consonants are deleted and the final stress thus resides on a codaless syllable (e.g., / țavá?/ $\rightarrow$ tsavá 'army'); (b) word final vowels are stressed when the vowel in the preceding syllable is reduced or deleted (e.g., /tijmór-u/ $\rightarrow$ tifmərú 'you ms.pl. will guard', /nafál-u/ $\rightarrow$ naflú 'they fell').

In addition to these cases of stress in V-final words, there is a group of nouns, called segolates, whose stem surfaces with penultimate stress re-

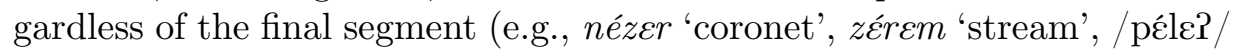
$\rightarrow$ péle 'wonder'). Following the historical development from pre-Hebrew to Biblical Hebrew, traditional analyses postulate a phonemic CVCC stem, where the final complex coda is simplified via epenthesis only after stress is assigned, but there are a few studies that propose an independent grammar for this group of nouns (Revell 1985; Garr 1989; Coetzee 1999; McCarthy 1999; Green 2004).

The stress pattern of segolates is maintained in contemporary Hebrew, but with no motivation for postulating a phonemic CVCC base (Bat-El 1989; 2012; Bolozky 1995). Consequently, we get (near) minimal pairs, where some C-final words get final stress and others do not (e.g., bókes

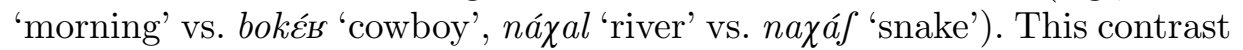
is further enhanced by loanwords with non-final stress (e.g., bí $a$ 'beer' vs. bisá 'capital city', banána 'banana' vs. mataná 'gift'). In addition, the glottal stop has been removed from the phonemic inventory of contemporary Hebrew, thus giving rise to final and penultimate stress in both C-final and V-final words (e.g., tsavá 'army' vs. tsavás 'neck', péle 'wonder' vs. ре́веk 'chapter'). ${ }^{13}$ One final change was in the syllable structure; Biblical Hebrew codas were moraic, as evident by compensatory lengthening (Lowenstamm \& Kaye 1986), but contemporary Hebrew codas lost their mora, as there is no phonological process sensitive to moraic structure.

Such changes have led to the inconsistent stress system in contemporary Hebrew nouns ( $(2.2)$, which is unnatural and unsystematic, and thus rather unstable. The changes were as follows:

${ }^{13}$ As noted in $\S 2.1$, other minimal pairs are distinguished by lexical category (e.g., bése $\chi$

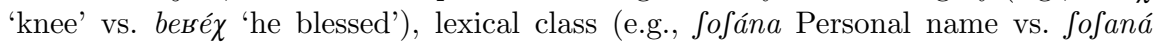
'rose'), or inflectional paradigm (e.g., ráts-a 'she ran' vs. ratsá 'he wanted'). I do not consider these minimal pairs for the purpose of this study as their contrast is drawn from the syntactic structure. 
(18) From Biblical Hebrew to contemporary Hebrew: constraint demotion

\begin{tabular}{|c|c|c|}
\hline & Biblical Hebrew & Contemporary Hebrew \\
\hline a. & $\mathbf{W}-\mathrm{BY}-\mathbf{P} \gg \mathrm{DEP}_{\mu}$ & $\mathrm{DEP}_{\mu} \gg \mathbf{W}-\mathbf{B Y}-\mathbf{P}$ \\
\hline b. & Trochee $\gg$ Iamb, Final & FinAL $\gg$ TROCHEE $\gg$ IAMB \\
\hline c. & \multicolumn{2}{|c|}{ FтBin, ${ }^{*}$ Fоот $-\sigma \gg{ }^{*}$ Fоот $-\mu$} \\
\hline d. & Parse $\gg$ AlignR $\gg$ NonFinai & AlignR $\gg$ NonFinality, Parse \\
\hline
\end{tabular}

W-BY-P was demoted below $\operatorname{DeP}_{\mu}$ and codas lost their moraicity (18a). The loss of moraic codas was actually the loss of a natural environment for final stress, and thus FinAL became a dominating constraint (18b).

Assuming Graf and Ussishkin's (2002) analysis, FTBIN persists in its dominant position and the ranking *FoOT- $\sigma \gg{ }^{*}$ FOOT- $\mu$ became irrelevant due to the loss of moraic codas (18c). However, under the analyses of Becker (2002) and Pariente and Bolozky (2014), FTBin is demoted in order to allow degenerate syllabic feet in words with final stress (e.g., $k a[d u ́ s]$ 'ball'). Finally, secondary stress on the lexical level did not persist in contemporary Hebrew, which means that PARSE was demoted below ALIGNR (18d). NonFinality keeps it position below AlignR (18d), which means that feet are right aligned with the prosodic word.

\section{Concluding remarks}

In this paper, I have presented a cycle of change in the stress system of Hebrew (skipping some steps in between): Biblical Hebrew (script-based) $\Rightarrow$ contemporary Hebrew (attested) $\Rightarrow$ post-Hebrew (predicted). The starting point was contemporary Hebrew with its unsystematic and unnatural stress system, i.e., a system that is not only inconsistent but also does not comply with universal principles. I assume that languages strive for regularity and naturalness, which thus constitute major forces in language change (though not the only ones). Therefore, I contended that contemporary Hebrew stress system cannot persist for too long, and the seeds of the change are already evident: words change their stress pattern (difference among generations) and the experimental results suggest that speakers prefer final stress in C-final words and penultimate stress in $\mathrm{V}$-final words.

Note that such a future system, although predicted to be more systematic, is not common in the sense that only final consonants are moraic. However, it is possible that the dependency in the final segment is just a necessary step in the development, which must accommodate the great 
number of words with final stress (mostly with C-final). The subsequent stage will probably be penultimate across the board, as was the case in the reconstructed pre-Hebrew (Florentin 2002; 2015; Blau 2010). This prediction is supported by Fainleib's (2008) experiment, where the preference for penultimate stress in general was higher in nonce words with low frequency vocalic patterns $(7 \mathrm{~b})$ than with high frequency vocalic patterns $(7 \mathrm{a})$. That is, when the interference of the lexicon is reduced, the preference for penultimate stress increases.

The entire U-shaped path is summarized below, with || indicating similar stress systems. In this paper I attended to three stages only: Biblical Hebrew $\Rightarrow$ contemporary Hebrew $\Rightarrow$ post-Hebrew I, but post-Hebrew II, and its similarity to pre-Hebrew are a further natural development.

(19) Back to the future

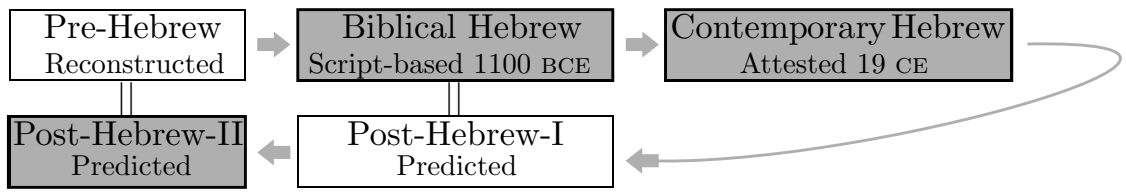

The similarity between the past and the future systems is attributed to the strive for a regular system complying with universal principles.

\section{Acknowledgements}

Earlier versions of this paper gained valuable input from the participants of OCP 13 (Winter 2016; Budapest), BHL 1 (Winter 2017; Bar-Ilan University), and the students in the "Biblical Hebrew Phonology and Morphology" course (Spring 2016; Tel-Aviv University). I appreciate Daniel Ahserov's invaluable contribution to the experimental study and the anonymous reviewers' helpful comments. The usual disclaimers apply.

\section{References}

Adam, Galit and Outi Bat-El. 2008. The trochaic bias is universal: Evidence from Hebrew. In A. Gavarró and M. J. Freitas (eds.) Language acquisition and development: Proceedings of GALA 2007. Newcastle: Cambridge Scholars Publishing. 12-24.

Adam, Galit and Outi Bat-El. 2009. When do universal preferences emerge in language development? The acquisition of Hebrew stress. Brill's Annual of Afroasiatic Languages and Linguistics 1. 1-28.

Allen, George D. and Sarah Hawkins. 1978. The development of phonological rhythm. In A. Bell and J. Hooper (eds.) Syllables and segments. Amsterdam: North-Holland. $173-185$. 
Aronoff, Mark. 1985. Orthography and linguistic theory: The syntactic basis of Masoretic Hebrew punctuation. Language 61. 28-72.

Bat-El, Outi. 1989. Phonology and word structure in Modern Hebrew. Doctoral dissertation. UCLA.

Bat-El, Outi. 1993. Parasitic metrification in the Modern Hebrew stress system. Linguistic Review 10. 189-210.

Bat-El, Outi. 1994. The optimal acronym word in Hebrew. In P. Koskinen (ed.) Proceedings of the 1994 annual conference of the canadian linguistic association. Toronto: Toronto Working Papers in Linguistics. 23-37. (in Hebrew)

Bat-El, Outi. 2000. The grammaticality of "extragrammatical" morphology. In U. Doleschal and A. M. Thornton (eds.) Extragrammatical and marginal morphology. München: Lincom Europa. 61-84.

Bat-El, Outi. 2005. The emergence of the trochaic foot in Hebrew hypocoristics. Phonology 22. 1-29.

Bat-El, Outi. 2008. Morphologically conditioned V- $\emptyset$ alternation in Hebrew: Distinction among nouns, adjectives and participles, and verbs. In S. Armon-Lotem, G. Danon and S. Rothstein (eds.) Current issues in generative Hebrew linguistics. Amsterdam \& Philadelphia: John Benjamins. 27-60.

Bat-El, Outi. 2012. Prosodic alternations in Modern Hebrew segolates. In M. Muchnik and T. Sadan (eds.) Studies in Modern Hebrew and Jewish Languages. Jerusalem: Carmel. 116-129.

Becker, Michael. 2002. Hebrew stress: Can’t you hear those trochees? MA thesis. Tel-Aviv University.

Becker, Michael. 2003. Lexical stratification of Hebrew: The disyllabic maximum. In Y. N. Falk (ed.) Proceedings of the 19th Annual Conference of the Israel Association for Theoretical Linguistics. Jerusalem: Israel Association for Theoretical Linguistic. 1-11.

Ben-David, Avivit. 2001. Language acquisition and phonological theory: Universal and variable processes across children and across languages. Doctoral dissertation. TelAviv University. (in Hebrew)

Ben-David, Avivit and Outi Bat-El. 2016. Paths and stages in the acquisition of Hebrew phonological word. In R. Berman (ed.) Acquisition and development of Hebrew: From infancy to adolescence. Amsterdam \& Philadelphia: John Benjamins. 39-68.

Blau, Joshua. 2010. The phonology and morphology of Biblical Hebrew. Jerusalem: The Academy of the Hebrew Language. (in Hebrew)

Bolozky, Shmuel. 1995. The segholates: Linear or discontinuous derivation? In O. Schwarzwald and Y. Schlesinger (eds.) Hadassah Kantor Jubilee Book. Ramat Gan: Bar-Ilan University. 17-26.

Bolozky, Shmuel. 2008. Hebrew verbs frequency list. Unpublished manuscript.

Bolozky, Shmuel. 2000. Stress placement as a morphological and semantic marker in Israeli Hebrew. Hebrew Studies 41. 53-82.

Bolozky, Shmuel and Michael Becker. 2006. Living lexicon of Hebrew nouns. Manuscript, University of Massachusetts Amherst.

Churchyard, Henry. 1999. Topics in Tiberian Biblical Hebrew metrical phonology and phonetics. Doctoral dissertation. University of Texas at Austin.

Coetzee, Andries W. 1999. Tiberian Hebrew Phonology: Focusing on consonant clusters. Assen: Van Gorcum. 
Cohen, Evan G. 2009. The role of similarity in phonology: Evidence from loanword adaptation in Hebrew. Doctoral dissertation. Tel-Aviv University.

Cohen, Evan G. 2013. The emergence of the unmarked: Vowel harmony in Hebrew loanword adaptation. Lingua 132. 66-79.

Cohen, Evan G., Vered Silber-Varod and N. Amir. 2018. The acoustics of primary and secondary stress in Modern Hebrew. Brill's Journal of Afroasiatic Languages and Linguistics.

Dresher, Bezalel Elan. 1981. Accentuation and metrical structure in Tiberian Hebrew. MIT Working Papers in Linguistics 3. 180-208.

Dresher, Bezalel Elan. 1994. The prosodic basis of the Tiberian Hebrew system of accents. Language 70. 1-52.

Dresher, Bezalel Elan. 2009. Stress assignment in Tiberian Hebrew. In C. Cairns and E. Raimy (eds.) Contemporary views on architecture and representations in phonological theor. Cambridge, MA: MIT Press. 213-224.

Fainleib, Lena. 2008. Default stress in unpredictable stress languages: Evidence from Russian and Hebrew. MA thesis. Tel-Aviv University.

Fainleib, Lena. 2013. Lexical distributions and productive generalizations of stress in Modern Hebrew nouns. A poster presented in the Phonology Conference, University of Massachusetts.

Florentin, Moshe. 2002. The Hebrew stress curve and what can we learn from it and from Samaritan Hebrew on stress in the Mishna. Leshonenu 64. 221-230. (in Hebrew)

Florentin, Moshe. 2015. Pre-Tiberian Hebrew and the heavy syllable law: A different approach for explaining the conditions of vowel reduction and lengthening during the pre-Tiberian stage of the language. Leshonenu 77. 161-176. (in Hebrew)

Garr, Randall W. 1989. The seghol and segholation in Hebrew. Journal of Near Eastern Studies 48. 109-116.

Gordon, Matthew. 2006. Syllable weight: Phonetics, phonology, typology. London \& New York: Routledge.

Graf, Dafna. 1999. Metrical structure of Modern Hebrew nominals. MA thesis. Heine University, Düsseldorf.

Graf, Dafna and Adam Ussishkin. 2002. Emergent iambs: Stress in modern hebrew. Lingua 113. 239-270.

Green, Antony D. 2004. Opacity in Tiberian Hebrew: Morphology, not phonology. ZAS Papers in Linguistics 37. 37-70.

Halle, Morris and Jean-Roger Vergnaud. 1987. An essay on stress. Cambridge, MA: MIT Press.

Hayes, Bruce. 1980. A metrical theory of stress rules. Doctoral dissertation. MIT.

Hayes, Bruce. 1989. Compensatory lengthening in Moraic Phonology. Linguistic Inquiry 20. 253-306.

Hayes, Bruce. 1995. Metrical stress theory. Principles and case studies. Chicago: The University of Chicago Press.

Horvath, Julia and Paul Wexler. 1994. Unspoken languages and the issue of genetic classification: The case of Hebrew. Linguistics 32. 241-269.

Itô, Junko and Armin Mester. 1995. The core-periphery structure of the lexicon and constraints on reranking. In J. N. Beckman, L. W. Dickey and S. Urbanczyk (eds.) Papers 
in Optimality Theory (University of Massachusetts Occasional Papers 18). Amherst, MA: GLSA. 181-209.

Itô, Junko and Armin Mester. 1999. The structure of the phonological lexicon. In T. Natsuko (ed.) The handbook of Japanese linguistics. Cambridge, MA \& Oxford: Blackwell. 62-100.

Khan, Geoffrey (ed.). 2013a. Encyclopedia of Hebrew Language and Linguistics online. Leiden: Brill.

Khan, Geoffrey. 2013b. Stress: Biblical Hebrew. In Khan (2013a).

Khan, Geoffrey. 2013c. Vowel length: Biblical Hebrew. In Khan (2013a).

LaCharité, Darlene and Carole Paradis. 2005. Category preservation and proximity versus phonetic approximation in loanword adaptation. Linguistic Inquiry 36. 223-258.

Liberman, Mark and Alan Prince. 1977. On stress and linguistic rhythm. Linguistic Inquiry 8. $249-336$.

Lieberman, Philip and Sheila Blumstein. 1998. Speech physiology, speech perception, and acoustic phonetics. Cambridge: Cambridge University Press.

Lowenstamm, Jean and Jonathan Kaye. 1986. Compensatory lengthening in Tiberian Hebrew. In L. Wetzels and E. Sezer (eds.) Studies in compensatory lengthening. Dordrecht: Foris. 97-132.

McCarthy, John J. 1979. Formal problems in Semitic phonology and morphology. Doctoral dissertation. MIT.

McCarthy, John J. 1999. Sympathy and phonological opacity. Phonology 16. 331-399.

Paradis, Carole and Darlene LaCharité. 1997. Preservation and minimality in loanword adaptation. Journal of Linguistics 33. 379-430.

Pariente, Itsik and Shmuel Bolozky. 2014. Stress shift and trochaic structures in the nominal system of Modern Hebrew. Brill's Annual of Afroasiatic Languages and Linguistics 6. $1-26$.

Rappaport, Malka. 1984. Issues in the phonology of Tiberian Hebrew. Doctoral dissertation. MIT.

Rendsburg, Gary A. 2007. Ancient Hebrew morphology. In A. Kaye (ed.) Morphologies of Asia and Africa. Volume 1. Winona Lake, IN: Eisenbrauns. 85-105.

Revell, Ernest J. 1985. The voweling of "i type" segolates in Tiberian Hebrew. Journal of the American Oriental Society 44. 319-328.

Revithiadou, Anthi, Kalomoira Nikolou and Despina Papadopoulou. 2015. Stress in the absence of morphological conditioning: An experimental investigation of stress in Greek acronyms. Journal of Greek Linguistics 15. 187-234.

Schwarzwald, Ora R. 1998. Word foreignness in Modern Hebrew. Hebrew Studies 39. $115-142$.

Segal, Osnat, Brach Nir-Sagiv, Liat Kishon-Rabin and Dorit Ravid. 2009. Prosodic patterns in Hebrew child directed speech. Journal of Child Language 36. 629-665.

Vihman, Marilyn, Rory DePaolis and Barbara Davis. 1998. Is there a "trochaic bias" in early word learning? Evidence from infant production in English and French. Child Development 69. 935-949.

Zadok, Gila. 2002. Abbreviations: A unified analysis of acronym words, clippings, clipped compounds and hypocoristics. MA thesis. Tel-Aviv University. 